\title{
Coordinance and role of aluminum in silicate glasses and melts
}

\author{
DANIEL R. NEUVILLE
}

${ }^{1}$ Géomatériaux, IPGP-CNRS, Université de Paris, 1 rue Jussieu, 75005 Paris, France, neuville@ipgp.fr

Aluminosilicate melts and glasses are very important composition to understand magmatic processes and are also materials widely used in several industrial applications (glass, glass-ceramic and ceramic materials). Their properties and structure, imposed by their chemical composition, drive for instance the eruptive dynamics of volcanoes as well as industrial processes of the glass-making industry.

But what is the speciation of the aluminum and how it varies according to the chemical composition and to the temperature?

The aluminum appears essentially in four or five fold coordination in glasses and melts. In alkali aluminosilicate compositions, $\mathrm{Al}$ is essentially in four fold coordination whereas the proportion of ${ }^{[5]} \mathrm{Al}$ increases with earth-alkaline substitution, or with alumina content and with temperature.

In the case of alkali aluminosilicate glass and melts, $\mathrm{Al}$ is compensated by alkali element and as a function of alkali element a new glass order can be observed.

In a second part, we can observe the presence of ${ }^{[5]} \mathrm{Al}$ in earth-alkaline aluminosilicate compositions. And its proportion varies as a function of $\mathrm{Al}$ and $\mathrm{T}$. In particular, as a function of temperature, ${ }^{[5]} \mathrm{Al}$ play different roles, close than glass transition temperature ${ }^{[5]} \mathrm{Al}$ can be a new network former and at more high temperature ${ }^{[5]} \mathrm{Al}$ can be insure the network dynamics.

In all case, ${ }^{[4]} \mathrm{Al}$ and ${ }^{[5]} \mathrm{Al}$ play important role on the structure and properties of silicate glasses and melts and they are the key of network dynamics and nucleation processes. 